\title{
Los Mensajes de Advertencia en las Cajetillas de Cigarrillo (MAC C): Una Mirada Lingüística Discursiva Comparativa
}

\author{
As Mensagens de Advertência nos Maços de Cigarro: \\ Um Olhar de Lingüística Discursiva Comparativa \\ Warning Messages in Cigarettes Packages: A Comparative \\ Linguistic-Discursive Approach
}

Omar SABAJ M.

(Pontificia Universidad Católica de Valparaíso - Chile)

\begin{abstract}
RESUMEN: Los mensajes de advertencia de las cajetillas de cigarrillos son una manifestación textual de una relación que se establece entre las autoridades sanitarias, las compañias tabacaleras y los consumidores de los productos del tabaco. Aunque son numerosos los estudios de este tipo de textos, casi no existen aproximaciones desde un punto de vista discursivo, semántico o lingüístico. A partir de la integración de categorías del análisis discurso, la semántica cognitiva y el estudio de la modalización lingüística, se analizó un corpus multilingüe y se determinó las similitudes y las diferencias que emergieron entre las divisiones geográficas del mismo. Para el análisis, se establecieron un conjunto de 8 categorías que fueron aplicadas sucesivamente en el corpus. De los resultados se infiere que, mientras algunas categorías distinguen claramente las zonas geográficas, otras se comportan de forma homogénea en todo el corpus. Tanto las diferencias como las similitudes encontradas nos permiten caracterizar las distintas condiciones de producción de dichos discursos en las zonas geográficas estudiadas.
\end{abstract}

PALABRAs-CLAVE: Mensajes de advertencia; análisis del discurso; condiciones de producción; análisis comparativo; corpus multilingüie.

RESUMO: As mensagens de advertência nos maços de cigarro são uma manifestação textual de uma relação que se estabele entre as autoridades da Saúde, os fabricantes e os consumidores dos produtos do tabaco. Ainda que sejam numerosos os estudos desse tipo de texto, quase não existem aproximações de um ponto do vista discursivo, semântico ou 
lingüístico. A partir de uma integração das categorias de análise do discurso, da semântica cognitva e da modalização lingüiśtica, analisou-se um corpus multilingue e determinouse as semelhanças e diferentas que emergiram das divições geográficas do mesmo. Para análise da coletânea foram estabelecidas um conjunto de oito categorias que nela foram sucessivamente aplicadas. Dos resultados da análise se infere que, enquanto algumas categorias se mostram distintas em algumas regiöes geográficas, outras de comportam de forma homogêna em todo o corpus. Tanto as diferenças assim como as semelhanças encontradas permitem-nos caracterizar as diferentes condições de produção destes discursos nas zonas geográficas estudadas.

PalavRas-CHAVE: mensagens de advertência; análise do discurso; condições de produção; análise comparativa; corpus multilingue.

ABSTRACT: Warning messages in the cigarette packages are a textual manifestation of a relation that establishes between the sanitary authorities, the tobacco companies and the consumers of tobacco products. Although the studies of this type of texts are numerous, almost do not exist approaches from a discursive, semantic or linguistic point of view. From the integration of categories of discourse analysis, cognitive semantics and the study of the linguistic hedging, a multilingual corpus was analyzed to determine the similarities and the differences that emerged between the geographic divisions of the corpus. For the analysis, a set of 8 categories were determined which were applied successively in the corpus. From the results, it can be inferred that, while some categories distinguish the geographic zones clearly, others behave of homogenously in all subdivisions of the corpus. As much the differences as the found similarities allow us to characterize the different production conditions of these texts in the studied geographic zones.

$K E Y$-WORDS: warning messages; discourse analysis; production conditions; comparative analysis; multilingual corpus.

\section{Introducción}

El crecimiento y continuo desarrollo de la económicamente poderosa industria tabacalera ha debido lidiar con los problemas de salud social que generan sus productos. Una manifestación textual de esta relación entre las autoridades de la salud, los productores de tabaco y los consumidores, son los mensajes de advertencia que aparecen en las cajetillas de cigarrillo. Aunque son muy numerosos los estudios de este tipo de textos (Wegrzyn, 1999; Hamond, Fong, MacDonald, Cameron \& Brown, 2003; Canadian Council For Tobacco Control, 2004; Health Canada, 2004a), casi no existen 
aproximaciones lingüísticas discursivas al respecto. El siguiente trabajo tiene por propósito analizar, a partir de la integración de categorías de la semántica cognitiva y algunos mecanismos discursivos, este tipo de textos. La base de este estudio se enmarca prioritariamente en el análisis del discurso, la semántica cognitiva y el estudio de la modalización lingüística, pero periféricamente se tratarán otros temas que pueden suscitar un interés para la psicolingüística, la historia o la publicidad.

En la investigación, se proveerá una definición operativa de estos mensajes como tipos o clases textuales específicas y, por medio de la recolección de un corpus multilingüe, se determinará las similitudes o diferencias lingüísticas que emergen de un análisis comparativo entre grupos geográficos. Luego de una breve panorámica histórica, se presentará los antecedentes teóricos de los mecanismos o dispositivos discursivos utilizados como categorías de análisis. Posteriormente, se presentará el corpus investigado junto con los procedimientos metodológicos seguidos en el trabajo. Finalmente, se expondrá los resultados y algunas conclusiones que se derivan del presente estudio.

\section{Antecedentes históricos}

Para comprender el origen y el contexto histórico del surgimiento de los mensajes de advertencia es conveniente hacer referencia a algunos hitos de la historia del tabaco y su uso. La cosecha de la planta del tabaco, originaria del continente americano, se remonta hasta unos 6 mil años antes del comienzo de la era cristiana. Según el exhaustivo estudio de Borio (2003), para el comienzo de nuestra era, las principales culturas aborígenes de nuestro continente utilizaban masivamente la hoja del tabaco con el fin de realizar ritos iniciáticos (como en la cultura Aguaruna del Perú) o con propósitos medicinales (cultura Maya). Es importante señalar que la hoja del tabaco no solamente se fumaba sino que presentaba una gran variedad de usos: se masticaba junto a otras hierbas, se destilaba en pócimas medicinales o simplemente se quemaba en ritos de la comunidad. Los Mayas y los Toltecas fueron las culturas que esparcieron el uso del tabaco en la mayor parte del continente americano. Se fumaba principalmente de dos formas. Los Toltecas lo mezclaban con resinas y lo fumaban en una pipa en una solemne ceremonia después de las comidas. Los Mayas lo enrollaban y formaban un pequeña vara que denominaban 
Sik'ar, el antecedente original de los cigarrillos actuales. El tabaco se introdujo en Europa por primera vez en 1556, siendo Francia el país, donde un monje revolucionario de nombre Thevet, plantó semillas de tabaco traídas del Brasil. En 1558, se empezó a cultivar en Portugal y desde 1559, gracias a las semillas que llevaba Francisco Hernandez de Toledo, médico personal de Felipe II, fue España la administradora más importante de tabaco de Europa. En el Reino Unido el tabaco se introdujo en 1565.

Para comprender el contexto en el cual surgen los mensajes de advertencia en las cajetillas de cigarrillos, solo destacaremos algunos datos curiosos en la historia del tabaco. Para esta exposición seguiremos el estudio de Borio (2003). Un primer dato curioso que cita este autor son los innumerables escritos de estudiosos botánicos de las plantas americanas en los que se realzan los beneficios medicinales del uso del tabaco. En el ámbito hispánico, Nicolás Monarde, un médico sevillano de renombre, enumera, ya en 1571, más de 36 enfermedades para las cuales el tabaco sería una cura infalible. En 1577, se traduce esa obra al inglés y los médicos británicos amplían la lista original de Monarde.

A los pocos años un artículo periodístico de un matutino londinense señala incluso que los médicos pretendían dejar en secreto las bondades del tabaco para la salud, para evitar así perder sus clientes, ya que el uso de la planta en cuestión significaría una cura total para cualquier dolencia humana.

Un antecedente histórico directo de los mensajes de advertencia en las cajetillas de cigarrillos es la publicación del texto Counterblaste to tobacco del Rey James I de Inglaterra en 1604. En el texto se exponen las distintas desventajas para la salud que el uso del tabaco conlleva, caracterizándolo también como una costumbre primitiva introducida desde países bárbaros que se puso rápidamente de moda en la aristocracia británica. La importancia del texto en cuestión no solo radica en su valor como documento histórico discursivo sino también en que, tal como indica Borio (2003), tuvo un impacto en la política económica de la época, ya que junto a este documento (en 1604), el Rey James I promulgó la primera ley que imponía un 4\% de impuesto a la comercialización del tabaco.

Desde la introducción del tabaco en Europa hasta la publicación del Rey James I se puede percibir un cambio radical: el tabaco pasa de tener una imagen positiva (cura enfermedades) a tener una imagen negativa (es 
una conducta bárbara que afecta a la salud). Este estigma negativo no ha cambiado (sino solo aumentado) hasta nuestros días, en los que nadie podría atribuir algún tipo de beneficio asociado al consumo de tabaco.

Durante el siglo XVII, en diversos ámbitos institucionales, políticos y religiosos, se comenzó a prohibir o restringir sistemáticamente el uso del tabaco. En 1624, por ejemplo, el Papa Urbano VIII amenazó con excomulgar a los feligreses que utilizaran tabaco. Pero en el siglo siguiente, exactamente en 1779, el Papa Benedicto XII abre la primera fábrica de tabaco ligada a una institución religiosa. Durante esa época, los principales reinados europeos comenzaron no solo a imponer cada vez más impuestos a la venta del tabaco sino también a monopolizar su comercialización. El monopolio se justificaba porque el cultivo de tabaco fue, durante los años de la colonización europea de Norte y Sudamérica, un producto clave en el desarrollo del intercambio de bienes comerciales entre el nuevo y el viejo mundo (Borio, 2003).

Desde entonces hasta el siglo XX, la historia del tabaco se abrió paso entre dos grandes columnas: su gran valor como producto comercial y su prohibición por instituciones de carácter político, religioso o sanitario.

En el siglo $\mathrm{XX}$, sin embargo, la historia del tabaco aparece necesariamente ligada a las circunstancias de la época. La historia de las guerras mundiales, la televisión, el cine, la publicidad y el diseño han estado directa o indirectamente ligada a la comercialización y uso del tabaco, principalmente, en forma de cigarrillos.

En 1912, un informe del doctor estadounidense Isaac Adler determina por primera vez una relación científica y directa entre el cáncer de pulmones y el consumo del tabaco. Comenzaron entonces a realizarse diversos estudios, tanto en Norteamérica como Europa, en los cuales se comprobaba estadística, biológica y fisiológicamente, una relación causal entre el consumo de tabaco y el cáncer de pulmones. En 1957, en Estados Unidos el senador Bennet impulsa un proyecto para regular la publicidad y el etiquetamiento de las cajetillas de cigarrillos. La utilización de los mensajes de advertencia en las cajetillas de cigarrillos comenzó 9 años después, en 1966. La autoridad sanitaria norteamericana encargada del control del tabaco y otras sustancias tóxicas (Surgeon General) determinó que todas las marcas de cigarrillos debían contener el siguiente mensaje: "Caution: Cigarette Smoking May Be Hazardous to Your Health”. Desde entonces, 
la práctica se comenzó a expandir por Europa, Sudamérica, Asia, Oceanía y África. La evolución de estos mensajes fue más o menos similar en los distintos países en que se impuso su utilización. Al principio, solo existía un solo mensaje para todas las marcas. Con el tiempo, los mensajes se fueron diversificando y se estipuló que debían rotar, aleatoriamente, sin importar la marca. Suiza fue el primer país (en 1973) que introdujo la rotación de mensajes en las cajetillas de cigarrillos: un conjunto de seis mensajes debía aparecer en todas las cajetillas y los cartones de cigarrillos que se comercializaran en ese país. Así también, desde el primer mensaje hasta nuestros días ha habido cambios gráficos importantes, que ilustraremos en el próximo punto, acerca de los mensajes de advertencia en dos países en particular, que representan la última tendencia en este tipo de textos a nivel mundial.

Desde los años noventa hasta nuestros días, el uso del tabaco y sus riesgos para la salud son dos temas que han fluido (mundialmente) entre dos fuerzas opuestas: los intereses comerciales de las grandes compañías tabacaleras y la cada vez más robusta evidencia científica sobre los irreparables efectos dañinos del uso del tabaco sobre la salud. La historia de la relación entre los científicos que han estudiado esos efectos y las compañías tabacaleras está llena de ardides, tanto así, que ha sido objeto de producciones cinematográficas. La historia puede resumirse en los siguientes puntos:

a) En un comienzo, la mayoría de los estudios sobre los efectos del tabaco en la salud eran realizados por científicos de las propias compañías tabacaleras, que debían mantener en secreto bajo juramento sus investigaciones.

b) Sólo hace muy poco tiempo (desde los años noventa), se han publicado o desclasificado los estudios realizados por esos científicos o por otros no pertenecientes a las compañías tabacaleras.

c) Aparecen (en Estados Unidos y en el Reino Unido) diversas demandas civiles o estatales contra las compañías tabacaleras. El contenido de las demandas era variado: desde las alteraciones químicas por parte de las tabacaleras que vuelven más adictivo a los productos hasta acusaciones de que estas compañías manipulan y fomentan el contrabando de tabaco como una forma de proteger el mercado. 


\subsection{Brasily Canadá: mensajes de última generación}

Sin duda Brasil y, especialmente, Canadá son los dos países que llevan la vanguardia en el desarrollo de mensajes de advertencia en productos tabáquicos. El desarrollo especial en el diseño, función e impacto de estos mensajes ha derivado de leyes civiles (la Ley $N^{\circ} 10167$, en Brasil y el Tobacco Act, en Canadá) que restringen fuertemente el uso, publicidad y comercialización de este. Desde el punto de vista gráfico, existen dos aspectos evidentes respecto a los mensajes brasileños y a los canadienses que los vuelven más particulares. En Canadá (en el año 1997) y en Brasil (en el año 2000), las autoridades sanitarias exigieron incorporar imágenes a los mensajes y cambiar y ampliar el espacio del mensaje sobre la superficie de la cajetilla. El lugar que tradicionalmente ocupaban estos mensajes en la cajetilla era la superficie lateral. Las leyes de estos países exigen en la actualidad que los mensajes aparezcan en las dos superficies principales y que ocupen desde un 30\% a un $40 \%$ de ellas. La incorporación de imágenes ha resultado en el uso de estrategias publicitarias, que para muchos parecen chocantes, similares a las controvertidas campañas de la casa italiana Benetton.

Canadá es un caso realmente excepcional. Su legislación prohíbe cualquier forma de publicidad (Canadian Council For Tobacco Control, 2004) a los productos del tabaco. Las autoridades canadienses fueron las primeras que exigieron además que las compañías tabacaleras retiraran de las cajetillas términos como "ligths" o "suaves" porque pueden inducir a inferencias erróneas a los consumidores. Dos anécdotas ilustran el compromiso canadiense respecto al consumo del tabaco. En el año 2004, se realizó en Canadá una fecha del campeonato mundial de Fórmula Uno. Como se sabe, la industria tabacalera es un auspiciador muy importante de este tipo de competencias automovilísticas. Al igual que en algunos países de Europa, en Canadá ya desde los años setenta se prohibió todo tipo de publicidad gráfica, de radio o de televisión de todos los productos tabáquicos, especialmente, en lo que concierne a actividades deportivas. Por otro lado, la industria tabacalera, a nivel mundial, ha sido uno de los auspiciadores más importantes de distintas actividades deportivas, especialmente, del automovilismo. Antes de la realización de la fecha correspondiente al campeonato mundial de Fórmula Uno en Canadá, las autoridades de la salud del gobierno canadiense amenazaron con cancelar la fecha del campeonato si los automóviles presentaban publicidad de cigarrillos. Esto 
provocó un gran conflicto en los equipos de Fórmula Uno ya que estos mantienen un contrato con las marcas de cigarrillos que significan un aporte monetario importante que financia en gran parte su funcionamiento. Cancelar una fecha del campeonato mundial de Fórmula Uno significaba pérdidas incalculables tanto para el comercio como para los organizadores y representantes de los equipos en cuestión. Dado que las autoridades canadienses no estaban dispuestas a transar, en el sentido que se violaran las estrictas leyes que prohíben el uso de publicidad de productos del tabaco en competencias deportivas y que, por otra parte, los equipos de Fórmula Uno no estaban dispuestos a perder una fecha del campeonato mundial, se llegó al siguiente acuerdo. Los automóviles borrarían (o harían ininteligibles) de sus autos la publicidad de cigarrillos y el gobierno canadiense aportaría la misma cantidad de fondos que cada compañía de tabacos paga por concepto de publicidad a cada equipo automovilístico por una fecha del campeonato mundial. A los canadienses, en definitiva, tampoco les convenía cancelar el evento. Para ejemplificar un caso concreto, solamente al equipo Ferrari, el gobierno canadiense pagó cerca de 12 millones de dólares para que confundiera los mensajes de la mundialmente popular marca de cigarrillos Malboro.

Otros dos efectos socioeconómicos curiosos del uso del tabaco a nivel internacional son los siguientes. En primer lugar, el hecho de que las compañías tabacaleras (junto con las empresas de productos alcohólicos) se han convertido, siguiendo la idea de "responsabilidad social", en una de las principales fuentes de financiamiento de obras de beneficencia a fondos destinados a la cultura y al deporte. En segundo lugar, específicamente en Canadá, la proliferación de las ventas de adhesivos con motivos gráficos que los fumadores utilizan para ocultar las chocantes fotos de las cajetillas.

\subsection{El estudio de los efectos de los mensajes de advertencia:} publicidad y psicolingüistica

En Canadá también, se han realizado distintos estudios para evaluar el impacto de los mensajes con fotos impuestos en el año 2000. Los estudios (Wegrzyn, 1999; Hamond, Fong, MacDonald, Cameron \& Brown, 2003; Health Canada, 2004a y b) se basan en encuestas que manejan las siguientes variables: 
a) Sexo

b) Edad

c) Nivel de educación

d) Cantidad de cigarros por día

e) Años fumando

f) Recuerdo de los mensajes

g) Conciencia de los mensajes

h) Intentos anteriores de dejar de fumar

i) Intención de dejar de fumar en los próximos seis meses

Las encuestas, que fueron realizadas cara a cara o por medio de llamadas telefónicas, también incluían preguntas acerca de la opinión que los sujetos tenían sobre el hecho de reforzar los mensajes tanto textual como gráficamente.

Estos estudios demostraron, entre otras cosas, que:

a) las mujeres recuerdan más y tienen más conciencia de los mensajes

b) tanto la edad como el nivel de educación, los años fumando y la cantidad de cigarros por día, son directamente proporcionales al recuerdo y a la conciencia por parte de los sujetos de los mensajes de advertencia

Así también, puesto que las encuestas fueron realizadas antes y después que los mensajes tuvieran fotos, se demostró que:

a) las imágenes en las cajetillas de cigarrillos aumentaron notablemente el recuerdo y la conciencia que los sujetos tienen de los mensajes

b) las imágenes aumentaron considerablemente la tasa de intentos de dejar de fumar por parte de los sujetos

Más allá de estos resultados, para el ámbito de la lingüística la campaña antitabáquica canadiense resulta interesante en tanto contó con la participación, entre otros, de publicistas y psicolingüistas que intentaron, con el diseño de los mensajes, manejar variables que provocaran una reacción conductual en el público. 


\section{Antecedentes Teóricos}

En este punto, nos centraremos en dos aspectos. Primero, proveeremos una definición operativa de los mensajes de advertencia como un tipo de textos determinado. En segundo lugar, presentamos los fundamentos teóricos de las categorías de análisis.

\subsection{Los mensajes de advertencia en las cajetillas de cigarrillos (MAC C) como un tipo de textos}

Para caracterizar los MAC C como un tipo de texto específico consideraremos los siguientes tres criterios: a) su función comunicativa, b) su ámbito de circulación y c) su función lingüística predominante (Ciapuscio, 1999). Respecto al primer punto, podemos sostener que la función comunicativa de dichos mensajes (tal como lo indica el nombre elegido para denominarlos) es advertir sobre los peligros o consecuencias que el consumo de tabaco reviste para la salud. El ámbito de circulación de dichos textos está compuesto, en principio, por dos participantes discursivos principales, a saber, los productores y los consumidores.

Sin embargo, en un análisis más preciso se deben considerar también las instituciones, organismos o autoridades sanitarias que son, a fin de cuentas, las que exigen legalmente que estos mensajes aparezcan en los envases del producto. El locutor discursivo de dichos textos debe atribuirse en última instancia a aquellas instituciones y no al productor de cigarrillos, que resulta ser un intermediario (obligado legalmente) del mensaje. Las condiciones de producción de los mensajes de advertencia están determinadas entonces por las leyes que impone una autoridad sanitaria, las que a su vez, están incluidas dentro de un marco legal especificado en las leyes de cada país. Desde una óptica general y previa al análisis, debido a las características de este tipo textual, su función lingüística predominante debiera ser la función apelativa o conativa, tal como la entiende Jakobson (1985).

Finalmente, cabe considerar que desde una óptica actual los textos (y los mensajes no son la excepción) se definen como fenómenos multimodales (Krees \& van Leeuwen, 2001), es decir, no solo presentan elementos lingüísticos, sino también icónicos o audiovisuales. Aunque en este trabajo 
no se analizarán las imágenes desde la teoría de la multimodalidad (sino que solamente se constatará su ocurrencia en las cajetillas), no se descarta incorporar este análisis en una pesquisa futura.

\subsection{Categorías para el análisis del discurso}

En este apartado, presentaremos las categorías discursivas utilizadas para el análisis del corpus. Definiremos, en primer término, el concepto de modalización según dos corrientes teóricas complementarias (Charaudeau, 1992; Hyland, 1998). Presentaremos, a continuación, la noción de tema desde una perspectiva discursiva general (van Dijk, 1983), amplia e intuitiva. Revisaremos, en seguida, (léase adecuaremos a nuestros objetivos) las nociones semánticas denominadas procesos y participantes (Jackendoff, 1983; Talmy, 2000). Finalmente, presentaremos algunas categorías gráficas y estadísticas, que serán utilizadas en el análisis.

\subsubsection{La modalización}

$\mathrm{Al}$ igual que muchas otras unidades léxicas terminológicas de la ciencia, el concepto de modalización presenta una polisemia variada que exige una demarcación clara de su alcance. Una forma aparentemente práctica de ver esta polisemia (ver Charaudeau \& Maingueneau, 2002) es adoptar un enfoque disciplinar, especificando en cada caso qué se entiende por modalización en lógica, en lingüística, en gramática o en semiótica, etc., distinciones que claramente exceden los propósitos de la presente investigación.

Una definición general para visualizar este concepto desde la teoría lingüística es la distinción de Bally (1932) entre modus y dictum. Mientras este último vehicula un contenido proposicional, el modus expresa la actitud del hablante en relación a ese contenido. Desde la teoría pragmática clásica la modalidad corresponde con la fuerza ilocucionaria que afecta al contenido proposicional de un acto de habla según el esquema $\mathrm{AH}=[\mathrm{FI}[\mathrm{P}]\}$, donde $\mathrm{AH}$ es un acto de habla compuesto por una fuerza ilocucionaria FI que afecta a una proposición P.

En primer lugar presentaremos una concepción de modalidad como un subcomponente de una noción más general denominada modalización, 
que se entiende como la manifestación discursiva de los participantes de la comunicación (Charaudeau, 1992). En segundo lugar, reseñaremos otro acercamiento teórico que se focaliza más en los recursos lingüísticos que se utilizan para expresar el grado de certeza, posibilidad, necesidad u obligación de un discurso. La modalidad en este sentido se acerca más a las nociones de atenuación o reforzamiento del contenido proposicional (Hyland, 1998). Tal como mostraremos más adelante, ambas aproximaciones son complementarias y apuntan desde dos enfoques a un mismo fenómeno.

\subsubsection{La modalización: los actos locutivos y las modalidades enunciativas}

Para Charaudeau y Maingueneau (2002), la modalización es una categoría conceptual que forma parte de un fenómeno lingüístico más complejo denominado 'enunciación'. El análisis de la modalización permite explicitar las posiciones del sujeto parlante en relación a un interlocutor, a él mismo o a un contenido específico; en otras palabras, esta noción nos permite analizar cómo la lengua se convierte en discurso. La modalización está compuesta por un cierto número de actos locutivos especificados por modalidades enunciativas según el esquema [Acto locutivo [modalidad enunciativa]\}.

Los actos locutivos pueden ser alocutivos (orientados hacia el otro), elocutivos (hacia el hablante) o delocutivos (orientado hacia un ello temático). Los actos alocutivos son aquellos actos en los que el locutor implica a su interlocutor y le impone el contenido de su enunciado. Los principales criterios que permiten determinar si un acto es alocutivo son:

a) La presencia del interlocutor por medio de pronombres personales (de segunda persona)

b) Presencia de nombres propios que identifican al interlocutor

c) El estatus de la oración (interrogativa, imperativa)

En los actos elocutivos, el locutor sitúa el contenido en relación a sí mismo, revelando su posición acerca de lo dicho. Los principales criterios para determinar si un acto es elocutivo son:

a) La ausencia del interlocutor 
b) Presencia del locutor por medio nombres propios o pronombres personales de primera persona

c) El estatus de la oración (exclamativa)

Finalmente, en los actos delocutivos el locutor impone el contenido como si él no fuera el responsable de la enunciación. En este tipo de actos tanto el locutor como el interlocutor están ausentes en el acto de la enunciación y el mensaje se interpreta como si el mundo hablara por sí mismo. Los criterios que permiten reconocer un acto delocutivo son:

a) Ausencia de pronombres personales (tanto de primera como segunda persona)

b) Presencia de marcas de impersonalidad (construcciones impersonales, pronombres neutros (Inglés $=$ it, Francés $=$ il, Alemán $=$ es) o de tercera persona singular

Es importante recalcar que, según Charaudeau (1992), la configuración (o expresión) lingüística entre el acto locutivo y las modalidades enunciativas puede ser explícita o implícita. Esto implica que no siempre la modalización se manifiesta en la superficie y es tarea del investigador develar su funcionamiento:

\footnotetext{
"Il Peut se faire enfin que la Modalisation ne soit exprimée par aucune marque linguistique, et que ce soit l'organisation d'ensemble de l'ennoncé qui, en relation avec d'autres indices verbaux ou paraverbaux (intonation, gestes, regards, ponctuation), et les particularités de la situation de communication, témoigne d'une modalité énonciative particulière" (Charaudeau, 1992: 573).
}

Como ya señalamos, cada tipo de acto locutivo se especifica en una modalidad enunciativa en la cual se precisa la relación que se establece entre el locutor y el interlocutor y, por lo tanto, la manera en que estos están implicados en el acto lingüístico.

En el Cuadro 1, se muestra la relación entre los tipos de actos locutivos y (solamente) las modalidades enunciativas (que utilizaremos en nuestro análisis). 
Cuadro 1: La modalización (adaptado de Charaudeau (1992: 629))

\begin{tabular}{|c|c|}
\hline \multicolumn{2}{|r|}{ LA MODALIZACIÓN } \\
\hline Tipo de acto & Modalidad enunciativa \\
\hline Alocutivo & $\begin{array}{ll} & \text { La interpelación } \\
\text { - La conminación / la prohibición }\end{array}$ \\
\hline Elocutivo & \\
\hline Delocutivo & $\begin{array}{ll}- & \text { La aserción: } \\
\text { - } & \text { La constatación } \\
- & \text { La evidencia } \\
\text { - } & \text { La posibilidad }\end{array}$ \\
\hline
\end{tabular}

En la interpelación, el locutor:

a) Expresa en su enunciado la identidad de un ser humano (o de una entidad que es concebida como tal)

b) Discrimina a su interlocutor dentro de un conjunto de interlocutores posibles

c) Se otorga un estatus que lo autoriza a interpelar

En la conminación o exhortación, el locutor:

a) Expresa en su enunciado una acción a realizar (a decir o a hacer)

b) Impone a su interlocutor esa acción de manera conminatoria

c) Se otorga un estatus de poder o autoridad absoluta

La prohibición, que es una variante de la conminación, presenta sus mismas características generales pero se diferencia en cuanto a que la acción a la que se exhorta al interlocutor no debe ser realizada.

Tanto la interpelación, como la conminación y la prohibición son modalidades enunciativas que especifican a los actos alocutivos.

La aserción es una modalidad enunciativa que especifica los actos delocutivos y se define como una proposición expresada que se tiene por verdadera. Sus subtipos (la constatación, la evidencia y la probabilidad) están marcados por elementos gramaticales, principalmente, adjetivos, adverbios y verbos modales. 


\subsubsection{La expresión lingüistica de la modalización: atenuación y reforzamiento}

Hyland (1998) trata el concepto de modalización desde una óptica distinta. Mientras que Charaudeau (1992) se ocupa de la modalización en cuanto esta noción permite analizar las posiciones de los sujetos hablantes en el discurso, siguiendo la distinción general entre modus y dictum, Hyland (1998) se centra en las manifestaciones lingüísticas del modus.

Esta aproximación presenta un corte más gramatical, en tanto, se interesa más por la expresión por medios lingüísticos del modus que de develar la relación entre los interlocutores del discurso o de la forma en que esos interlocutores se relacionan con un tema específico. Aun así, ambas aproximaciones se refieren a un mismo fenómeno, a saber, la expresión de elementos actitudinales en la lengua en uso.

El estudio de la modalización, desde el punto de vista de Hyland (1998), parte del supuesto que esta se esparce en distintos niveles lingüísticos. La modalización se puede expresar tanto en unidades léxicas como en estructuras sintácticas, inclusive, en ciertos patrones prosódicos. El marco conceptual que Hyland (1998) propone incluye, entre varias otras categorías, la distinción entre elementos enfatizadores (boosters) y elementos inhibidores o mitigadores (downtoners) del contenido proposicional del discurso. Esta distinción resulta especialmente importante para analizar cómo se enuncian los contenidos proposicionales de los mensajes de advertencia en las cajetillas de cigarrillos, es decir, si tienen una forma reforzada o una más bien debilitada.

Aunque en este trabajo no se ahondará en las interacciones entre ambas concepciones de la modalización, es importante señalar que estas interacciones existen. Como ejemplo, podemos referirnos a los siguientes enunciados:

a) Es probable que Juan llegue a tiempo.

b) Es muy probable que Juan llegue a tiempo / Es poco probable que Juan llegue a tiempo

En el caso a), la teoría de la enunciación (Charaudeau, 1992) nos permite reconocer que se trata de un acto delocutivo especificado por una 
modalidad de posibilidad. En el caso b), en cambio es la teoría de la modalización lingüística (Hyland, 1998) la que nos permite hablar de una posibilidad reforzada, en la primera versión y de una posibilidad debilitada, en la segunda versión.

\subsubsection{El tema}

La noción de tema puede remitirse al nivel macroestructural de van Dijk (1983), entendiéndose como asunto general del discurso. En este estudio, entendemos el término "tema" de forma laxa e intuitiva como un conjunto de ideas asociadas a un ámbito de conocimiento o dominio, que puede ser general o específico y que se manifiesta principalmente en elementos nominales. Consideraremos además que los temas pueden constituirse en estructuras jerárquicas, es decir, un tema general puede estar compuesto por uno o varios temas más específicos. Esta categoría nos será de gran utilidad para descubrir si existen diferencias o similitudes entre los contenidos que se expresan en los subcomponentes (geográficos) que componen nuestro corpus de análisis.

Esta definición conceptual no es de fácil aplicación operativa, ya que implica definir cómo se relaciona jerárquicamente un dominio con otro y cuál es el grado de especificidad o generalidad entre cada tema. Debido a lo anterior, al analizar los temas se procedió a partir de una metodología principalmente emergente, cuyos criterios se definen en la sección 5.4.4.

\subsubsection{Los tipos de procesos y sus participantes}

Los términos "procesos" y "participantes" presentan, en este estudio, una definición restringida, que es a su vez una integración de dos teorías de la semántica cognitiva (Talmy, 2000; Jackendoff, 1983).

Los procesos los identificaremos con los predicados semánticos básicos

de Jackendoff (1983). Según este autor, todos los predicados de una lengua se pueden descomponer en predicados semánticos básicos que están a la base de su estructura léxico conceptual.

Por su parte, clasificaremos los participantes semánticos siguiendo las distinciones de Talmy (2000), según sean animados o inanimados. Cabe 
destacar que, desde esta perspectiva se considera animado a un participante que explícita o implícitamente implique una entidad animada. En este sentido, tanto un pronombre personal como el sustantivo "salud" se incluyen dentro de esta categoría.

En el Cuadro 2, se muestran las interacciones que se pueden establecer entre estos dos enfoques.

Cuadro 2: Procesos y participantes

\begin{tabular}{|l|l|}
\hline Participante & Tipo de predicados \\
\hline + Animado & $\begin{array}{l}\text { Mover } \\
\text { Moverse }\end{array}$ \\
\hline + / - Animado & $\begin{array}{l}\text { Causar } \\
\text { Llegar a un lugar } \\
\text { Llegar a un estado } \\
\text { Ser / estar }\end{array}$ \\
\hline
\end{tabular}

En el Cuadro 2, se presentan las interacciones posibles entre tipos de predicados y de participantes. Se pueden establecer algunas restricciones entre los participantes animados y los predicados "mover" y "moverse" mientras que los otros predicados no implican ninguna restricción sobre el participante que los inicia. Estas relaciones son prototípicas en cuanto también pueden aparecer expresiones metafóricas (personificaciones) que no son afectadas por estas restricciones. Debido a lo anterior, analizaremos en forma independiente ambas categorías. Las relaciones entre estos enfoques no son directas ni fijas, pero funcionan como grandes directrices para poder caracterizar los procesos y los participantes semánticos de un evento.

\subsubsection{Categorías gráficas para el análisis $M A C C$}

Considerando que, tal como hemos constatado en un análisis previo de los datos, existen mensajes con características gráficas diferentes, describiremos estas diferencias en nuestro análisis. Cabe especificar que, en aquellos mensajes que presenten fotos, no ahondaremos en un análisis semiótico de estos medios gráficos sino que solamente constataremos su ocurrencia. Hechas estas aclaraciones, presentamos a continuación las categorías gráficas que constataremos en el estudio: 
Cuadro 3: Categorías gráficas para el análisis de los mensajes

\begin{tabular}{|l|l|l|}
\hline Tiene Fotos & + & - \\
\hline Posición del mensaje & Frontal & Lateral \\
\hline Cantidad de mensajes por cajetilla & 2 & 1 \\
\hline
\end{tabular}

\subsubsection{Unidades estadísticas para el análisis de los textos}

Además de las categorías netamente lingüísticas que utilizaremos en este estudio, analizaremos los mensajes de cada subcorpus, en una unidad estadística, específicamente, la cantidad promedio de palabras. Para este cálculo utilizaremos la siguiente fórmula:

$\Sigma \mathrm{P} / \mathrm{N}^{\circ} \mathrm{M}$, o sea, el total de palabras de un subcorpus divido por la cantidad de mensajes que lo conforman.

\section{El estudio}

Tal como señaló en la introducción, la siguiente investigación tiene por objetivo determinar y describir las similitudes y diferencias lingüísticas que puedan existir entre los mensajes de advertencia en las cajetillas de cigarrillos en distintos continentes o subcontinentes. El enfoque de este análisis es prioritariamente lingüístico discursivo ya que las categorías utilizadas se enmarcan dentro de esos niveles. Se incluyen, además, categorías de tipo más puramente gramatical, así como nociones gráficas y estadísticas. Es importante destacar la importancia de la aproximación discursiva de este estudio ya que la mayoría de las investigaciones que se han realizado de este tipo de discursos se han centrado mayoritariamente en aspectos legales, distinguiendo las exigencias que cada país impone para la venta de productos relacionados con el tabaco.

Esta investigación se enmarca en lo que Sampieri, Collado y Baptista (2003) denominan estudios descriptivos. Según su definición, este tipo de trabajos pretenden "medir o recoger información de manera independiente o conjunta sobre los conceptos o variables a los que refieren" (Sampieri et al., 2003: 119). Los autores señalan además que este tipo de investigaciones ofrece la posibilidad de realizar predicciones o relaciones entre las variables. 
Aunque estos autores separan este tipo de investigaciones descriptivas de otras con un corte más explicativo, concordamos con Titscher, Meyer, Wodak y Vetter (2000:7) en el hecho que:

“...description may have additional hidden aims and seek to describe the behaviour of actors in particular social fields. Such investigations do not aim to account for quantifiable distributions but rather to document spheres of existence, and sometimes also to go beyond description and explain the rules which determine them".

Tal como señalan Sampieri et al. (2003), es muy difícil encontrar estudios que sigan de forma pura uno de los posibles tipos. Generalmente, lo que ocurre es que hay un predominio de una de las orientaciones, ya que tal como afirman estos autores (Sampieri et al., 2003; Titscher et al., 2000), en la mayoría de las investigaciones se mezclan aspectos exploratorios, descriptivos, correlacionales y explicativos.

El enfoque adoptado en esta investigación mezcla métodos cualitativos y cuantitativos. La importancia de la complementación entre ambos enfoques radica en que, tal como afirman Sampieri et al. (2003), aún no se ha demostrado que uno sea mejor que el otro y, por lo tanto, es difícil encontrar un estudio puramente cuantitativo o cualitativo. Lo cualitativo se deduce del tipo de las categorías utilizadas y lo cuantitativo, del análisis comparativo (usando una estadística básica, no correlacional ni paramétrica) de la ocurrencia de esas categorías en cada subcorpus).

\subsection{Pregunta de investigación}

La pregunta que se busca responder en la presente investigación es la siguiente:

¿Cuáles son las similitudes y/o diferencias lingüístico-discursivas (cualitativas y cuantitativas) entre los mensajes de advertencia en las cajetillas de cigarrillos de distintos continentes?

\subsection{El corpus $^{1}$}

En el Cuadro 4, se presenta la conformación del corpus de análisis:

1 El corpus completo (61 mensajes, 4 grupos geográficos y 13 países) es parte del ANEXO 1 
Cuadro 4: Conformación del corpus MAC C

\begin{tabular}{|c|c|c|c|c|}
\hline & Subcorpus & Países & Mensajes & imágenes \\
\hline & Norteamérica & $\begin{array}{c}\text { Estados Unidos } \\
\text { Canadá }\end{array}$ & 20 & 16 \\
\hline & Europa & $\begin{array}{c}\text { España } \\
\text { Francia } \\
\text { Holanda } \\
\text { Italia } \\
\text { Suecia } \\
\end{array}$ & 21 & 0 \\
\hline & Asia y Oceanía & $\begin{array}{c}\text { Taiwán } \\
\text { Japón } \\
\text { Australia }\end{array}$ & 13 & 0 \\
\hline & Sudamérica & $\begin{array}{c}\text { Chile } \\
\text { Argentina } \\
\text { Brasil } \\
\end{array}$ & 7 & 2 \\
\hline Totales & 4 & 13 & 61 & 18 \\
\hline
\end{tabular}

Un aspecto que se debe considerar respecto del corpus es su carácter no homogéneo.

En algunas zonas geográficas (o subcorpus), como en Norteamérica y Europa, se recolectó el universo de los mensajes. En Sudamérica y en Asia y Oceanía, los mensajes no representan el universo y corresponden solo a una muestra de los mensajes disponibles. Además la parte central del análisis serán los mensajes (61) y la división adoptada será por zona geográfica o subcorpus; esto implica que, no se revisarán las diferencias internas entre los países que constituyen cada subcorpus. Declarar la forma del análisis (divisiones adoptadas) es de vital importancia al momento de comparar cuantitativamente los resultados obtenidos debido a que los tipos de categorías analizadas se pueden referir a un mensaje completo o a una palabra en el mensaje, razón por la cual, los datos deben presentarse debidamente normalizados respecto a la unidad que atañe a la categoría.

Otro aspecto importante respecto a los mensajes dice relación con el idioma en que se presentan. La mayoría de los mensajes aparecen en su idioma original, pero en algunos casos se han traducido al español o al inglés de forma de facilitar su análisis y presentación. Es el caso de los mensajes suecos, los japoneses y los taiwaneses. En el caso de los mensajes suecos y japoneses, las traducciones fueron hechas por las autoridades 
sanitarias de cada país. En el caso de los mensajes taiwaneses, la traducción fue hecha por una profesora taiwanesa de español ${ }^{2}$.

\subsection{Procedimientos de recolección y de análisis de los datos}

La recolección del corpus de estudio se llevó a cabo durante la segunda mitad del año 2003 y la primera mitad del 2004 por diferentes medios: de forma directa en comunicaciones personales del investigador y, a menudo, gracias a los recursos libres en internet y a la colaboración de investigadores internacionales. El corpus representa el universo de los mensajes que circulaban y aún circulan en los países que componen el corpus (Ver Cuadro 4) y conforman la distinción comparativa por grupos geográficos.

Para el análisis de los datos se utilizó el software Atlas/ti 4.2. Este software, basado en los principios metodológicos de la Teoría Fundada, permite el análisis cualitativo y cuantitativo de datos y funciona bajo el paradigma de la codificación recursiva, es decir, a partir de la aplicación de unas categorías previas al conjunto de datos que se van redefiniendo según la emergencia de nuevos fenómenos. La ventaja de la utilización de dicho programa se basa en que una vez que se han codificado los datos, se puede recuperar la información (generación de informes) según distintos criterios, lo que a su vez, facilita su visualización y comparación según las agrupaciones que previamente se ha realizado del corpus.

En este caso, primero se agruparon los mensajes por continente en forma de documentos y luego se procedió a aplicar consecutivamente y recursivamente las categorías de análisis utilizadas. En el Cuadro 5, se expone un resumen de estas categorías:

\footnotetext{
2 Quisiera agradecer especialmente a la Dra. Felisa Lu de la Providence University \& NCKU, Taiwán, por su colaboración en la recolección y traducción de los mensajes de ese país.
} 
Cuadro 5: Resumen de categorías y subcategorías de análisis

\begin{tabular}{|l|l|}
\hline Categorías de análisis & Subcategorías \\
\hline Tipos de Acto & Actos elocutivos \\
& Actos elocutivos \\
& Actos delocutivos \\
\hline Modalidades enunciativas & Interpelación \\
& Conminación \\
& Prohibición \\
& Constatación \\
& Evidencia \\
& Posibilidad \\
\hline Modalización lingüística & Reforzadores \\
& Mitigadores \\
\hline Temas & Categoría emergente no apriorística \\
\hline Procesos & Causar \\
& Mover \\
& Moverse \\
& Llegar a un estado \\
& Llegar a un lugar \\
& Ser / estar \\
& Estar- ndo \\
\hline Estadística & Animado \\
& Inanimado \\
\hline Participantes & Presenta imagen \\
& No presenta imagen \\
& Posición del mensaje lateral \\
& Posición del mensaje Frontal \\
& Presenta un mensaje por cajetilla \\
& Presenta dos mensajes por cajetilla \\
\hline & Cantidad de palabras \\
& Cantidad de mensajes por subcorpus \\
& Promedio de palabras por mensaje en cada subcorpus \\
\hline & \\
\hline &
\end{tabular}

\section{Análisis}

El análisis de los datos aparecen en el Anexo 1, que está compuesto por:

a) El corpus completo (descrito en la sección 3.2):

Se presentan todos los mensajes agrupados por zonas geográficas. En cada zona geográfica además, se especifica el país del cual provienen. 
b) Informes generados por el programa Atlas/ti 4.2 respecto de las categorías de análisis:

Tal como mencionamos anteriormente (sección 3.3), el programa utilizado en el análisis permite la recuperación de información a través de informes por cada una de las categorías o códigos utilizados para el análisis. Estos informes consisten básicamente en las citas asociadas a cada código en cada una de las subdivisiones del corpus. Las citas pueden corresponder, bien a un mensaje completo, bien a una parte de un mensaje. En esta sección del Anexo 1, se pueden visualizar el criterio de la aplicación de las categorías a los fragmentos textuales que componen cada subcorpus.

c) Una red conceptual temática (ver Red Conceptual Temática 1) generada a partir del análisis temático:

Esta red es generada automáticamente por el programa a partir de las codificaciones temáticas realizadas sobe los mensajes. Cuando un mismo mensaje ha sido codificado con más de un tema, el programa asocia automáticamente ambos temas. La Red Conceptual Temática 1 corresponde a la asociación que Atlas/ti 4.2 ha realizado a partir de la codificación propuesta por el investigador (ver sección 5.4.4).

\section{Resultados}

En esa sección, presentamos los resultados del análisis del corpus de estudio. Para la exposición, seguiremos el orden en que aparecen las categorías en el Cuadro 5.

\subsection{Tipos de actos}

En la Tabla 1, se presentan los resultados respecto de los tipos de actos que aparecen en los mensajes de advertencia de las cajetillas en nuestro corpus de análisis. 
Tabla 1: Porcentaje de aparición de los tipos de actos por continente

\begin{tabular}{|c|c|c|c|c|c|}
\hline & $\begin{array}{c}\text { Norte- } \\
\text { américa }\end{array}$ & Europa & $\begin{array}{c}\text { Asia y } \\
\text { Oceanía }\end{array}$ & Sudamérica & Ejemplos \\
\hline Alocutivos & $25 \%$ & $28,60 \%$ & $15,40 \%$ & 0 & $\begin{array}{c}\text { Tobacco may be harmful to your } \\
\text { health Avoid excessive smoking/ } \\
\text { Smoking when pregnant harms } \\
\text { your baby }\end{array}$ \\
\hline Delocutivos & $75 \%$ & $71,40 \%$ & $84,60 \%$ & $100 \%$ & $\begin{array}{c}\text { Cigaratte Smoke Contains Carbon } \\
\text { Monoxide / Il fumo uccide }\end{array}$ \\
\hline Elocutivos & $0 \%$ & $0 \%$ & $0 \%$ & $0 \%$ & \\
\hline
\end{tabular}

Tal como se observa en la Tabla 1, los tipos de actos que priman en los mensajes de advertencia en las cajetillas de cigarrillos del corpus son los actos delocutivos. Como señalamos en el marco teórico, en este tipo de actos, tanto el locutor como el interlocutor están ausentes y el discurso se presenta como si el mundo hablara por sí mismo (Charaudeau, 1992). La mayoría de estos mensajes delocutivos, aparecen textualizados con formas no personales del verbo, por ejemplo, "Fumar es malo para la salud". En la tabla se observa que los actos delocutivos representan el 100\% de los mensajes que aparecen en el corpus sudamericano, seguido por el corpus de Asia y Oceanía con un 84,6\%. Luego, se ubica el corpus norteamericano con un $75 \%$ y, finalmente, el corpus europeo con un $71,4 \%$. Por el carácter de los actos delocutivos, podemos inferir que la mayor aparición de estos en un corpus dado implica una realización más indirecta del acto de advertencia, ya que se advierte de modo general sobre una acción que no hace referencia a un interlocutor específico. En este sentido, se puede establecer una relación inversa entre el porcentaje de los actos delocutivos y el carácter directo de la advertencia. El corpus sudamericano es el más débil en sus advertencias, puesto que el total de sus mensajes son de tipo delocutivo. Por el contrario, el corpus europeo aparece como el más directo en sus advertencias, ya que presenta el menor número de mensajes enunciados de forma genérica, sin una referencia a un interlocutor específico.

A los actos delocutivos, se oponen los actos alocutivos y elocutivos, en los que, por medio de marcas (pronombres personales, posesivos, etc.) aparece el receptor (en los alocutivos) y el emisor (en los elocutivos). Respecto de los actos alocutivos y en consonancia con los datos recién presentados, el corpus europeo aparece con el mayor porcentaje de mensajes que hacen referencia al interlocutor, por ejemplo, en el caso del siguiente mensaje sueco: 
"Smoking is addictive. Nicotine makes you physically dependent in a way similar to that of heroin or cocaine". La tendencia de la ocurrencia de los actos delocutivos va (de menor a mayor) en el siguiente orden: Europa $<$ Norteamérica $<$ Asia y Oceanía $<$ Sudamérica.

Los actos elocutivos no aparecen en el corpus analizado, es decir, la expresión directa de la voz del enunciador no parece ser un mecanismo que cumpla una función en este tipo de textos.

Es importante señalar que, aunque genéricamente hemos denominado como mensajes de advertencia al objeto de estudio de este trabajo, en el análisis vemos que esta etiqueta genérica no siempre se aplica, ya que los mensajes cumplen una variada gama de funciones que no siempre se ajustan a lo que en el lenguaje general denominamos "advertencia".

Aunque el propósito de nuestro trabajo es comparar los mensajes por grupos continentales (esto es, mirar las filas y no las columnas), en algunos casos comentaremos también el comportamiento de las categorías dentro de cada grupo continental. En este sentido, solamente deseamos mostrar que en el caso de los tipos de actos existe una constante que es independiente del subcorpus analizado, a saber, que en cualquiera de ellos existen más actos delocutivos, que en el nivel intermedio siempre se encuentran los actos alocutivos y que, finalmente, los actos elocutivos no aparecen en ninguna zona geográfica.

\subsection{Modalidades enunciativas}

En la Tabla 2, se presentan los resultados respecto de las modalidades enunciativas asociadas a los actos alocutivos revisados en el punto anterior. Cabe señalar que tanto en este caso como en el siguiente (modalidades enunciativas en los actos delocutivos), los datos presentados corresponden al porcentaje respecto al total de las apariciones y no respecto al total de los tipos de actos. Esto debido a que en muchos casos se puede aplicar una doble clasificación a cada mensaje (mensajes que interpelan y a la vez conminan o mensajes que a la vez constatan y evidencian) 
Tabla 2: Modalidades enunciativas en los actos elocutivos

\begin{tabular}{|c|c|c|c|c|l|}
\hline & $\begin{array}{c}\text { Norte- } \\
\text { américa }\end{array}$ & Europa & $\begin{array}{c}\text { Asia y } \\
\text { Oceanía }\end{array}$ & Sudamérica & \multicolumn{1}{|c|}{ Ejemplos } \\
\hline Interpelación & $60 \%$ & $83 \%$ & $66,7 \%$ & 0 & $\begin{array}{l}\text { You're not the only one } \\
\text { smoking this cigarette }\end{array}$ \\
\hline Conminación & $20 \%$ & $16,7 \%$ & 33,3 & 0 & Protegéz les enfants \\
\hline Prohibición & $20 \%$ & 0 & 0 & 0 & $\begin{array}{l}\text { Ne leur faites pas } \\
\text { Respirer votre fumée }\end{array}$ \\
\hline
\end{tabular}

En la Tabla 2, podemos observar que es la interpelación la modalidad enunciativa más frecuente en el corpus. Esta modalidad, que corresponde a una subespecificación de los actos alocutivos, está representada por mensajes como «You are not the only one smoking this cigarette» en donde se identifica a un interlocutor específico (un fumador). Tanto la conminación, entendida como una exhortación a realizar una acción por parte de un interlocutor, como la prohibición, concebida como una conminación a no realizar una acción presentan un menor número de ocurrencias. Si observamos las diferencias entre continentes, el corpus sudamericano no presenta ninguna ocurrencia de este tipo de modalidades (puesto que no aparecen actos elocutivos), lo que es directamente deducible de los datos de la Tabla 1; por su parte, el corpus norteamericano es el único en que aparece la prohibición, en el que se llama al interlocutor a no realizar una acción. Por último, la conminación tiene el mayor porcentaje de aparición en el subcorpus de Asia y Oceanía.

En la Tabla 3, se muestran los resultados de las modalidades enunciativas que subespecifican a los actos delocutivos.

Tabla 3: Modalidades enunciativas en los actos delocutivos

\begin{tabular}{|c|c|c|c|c|l|}
\hline & $\begin{array}{c}\text { Norte- } \\
\text { américa }\end{array}$ & Europa & $\begin{array}{c}\text { Asia y } \\
\text { Oceanía }\end{array}$ & Sudamérica & \multicolumn{1}{|c|}{ Ejemplos } \\
\hline Constatación & $50 \%$ & $40 \%$ & $47,61 \%$ & $44,44 \%$ & $\begin{array}{l}\text { Cigarettes are highly } \\
\text { addictive }\end{array}$ \\
\hline & & & & $\begin{array}{l}\text { Each year, the equivalent } \\
\text { of a small city dies from } \\
\text { tobacco use }\end{array}$ \\
\hline Evidencia & $42,30 \%$ & $52 \%$ & $47,61 \%$ & $44,44 \%$ & Fumar Puede matar \\
\hline
\end{tabular}


En primer término, se puede establecer que tanto la constatación como la evidencia son las formas más comunes de modalidades enunciativas al momento de realizar un acto delocutivo en cualquiera de las zonas geográficas estudiadas. La constatación aparece más en el subcorpus norteamericano (50\%), mientras que la evidencia es la modalidad más importante en el subcorpus europeo (52\%). Ambas modalidades ocupan un lugar intermedio (respecto de Norteamérica y Europa) en Asia y Oceanía y en Sudamérica. En estas zonas geográficas no existe diferencia respecto del uso de una u otra modalidad. Es decir, en Asia y Oceanía y en Sudamérica la constatación y la evidencia son recursos que se emplean homogéneamente $(47,61 \%$ y $44,44 \%$, respectivamente). La posibilidad es un recurso más frecuente en Sudamérica que en cualquier otra zona geográfica $(11,11 \%)$.

\subsection{Modalización lingüistica}

En la Tabla 4, se exponen los enfatizadores y los mitigadores en el corpus de estudio.

Tabla 4: Enfatizadores y mitigadores

\begin{tabular}{|c|c|c|c|c|c|c|c|}
\hline \multicolumn{3}{|c|}{ Enfatizadores } & \multicolumn{4}{c|}{ Mitigadores } \\
\hline $\begin{array}{c}\text { Norte- } \\
\text { américa }\end{array}$ & Europa & $\begin{array}{c}\text { Asia y } \\
\text { oceanía }\end{array}$ & Sudamérica & $\begin{array}{c}\text { Norte- } \\
\text { américa }\end{array}$ & Europa & $\begin{array}{c}\text { Asia y } \\
\text { oceanía }\end{array}$ & Sudamérica \\
\hline $\begin{array}{c}\text { Greatly } \\
\text { Serious } \\
\text { seriously } \\
\text { highly }\end{array}$ & $\begin{array}{c}\text { Gravement } \\
\text { Ernstige } \\
\text { gravemente } \\
\text { dramatically } \\
\text { serious } \\
\text { increases } \\
\text { increase }\end{array}$ & fácilmente & Mais & $\begin{array}{c}\text { May } \\
\text { May } \\
\text { can }\end{array}$ & $\begin{array}{c}\text { Pert } \\
\text { puede }\end{array}$ & $\begin{array}{c}\text { May } \\
\text { can }\end{array}$ & puede \\
& & & & & & \\
& & & & & & \\
\hline
\end{tabular}

Los datos que aparecen en la Tabla 4 revelan que en dos de los cuatro subcorpora analizados, los enfatizadores ocupan un lugar más importante que los mitigadores: la excepción es el corpus de Asia y Oceanía. El subcorpus sudamericano no presenta diferencias al respecto, ya que tiene las misma cantidad de enfatizadores y mitigadores (y se trata solamente de una ocurrencia).

El corpus europeo es el que tiene una mayor presencia de enfatizadores, seguido del subcorpus de Norteamérica. A continuación, aparece el 
subcorpus sudamericano y, por último, el subcorpus de Asia y Oceanía. Desde un punto de vista general, se puede establecer que la categoría de los enfatizadores es un elemento que distingue los subcorpora de nuestro corpus de análisis. De la Tabla 4 podemos deducir además, que las formas en que estos enfatizadores se concretan corresponden a adverbios de cantidad (mais); a adjetivos (serious, ernstige); a adverbios de modo (gravemente, seriously) y, en el caso del subcorpus europeo, a verbos (increase, increases).

En lo que respecta a los mitigadores, podemos establecer que no existen mayores diferencias en la cantidad de mitigadores que aparecen a excepción del corpus de Asia y Oceanía que es el que más se diferencia por su menor cantidad de mitigadores. Al contrario de los enfatizadores, que aparecen en formas gramaticales variadas, la totalidad de las formas que se utilizan para mitigar corresponden verbos modales (Peut, puede, can, may).

\subsection{Temas}

En la Tabla 5 aparecen los temas que emergieron del análisis del corpus de estudio.

Tabla 5: Temas de los mensajes por continente

\begin{tabular}{|l|l|c|c|c|c|}
\hline $\mathbf{N}^{\mathbf{o}}$ & \multicolumn{1}{|c|}{ Temas } & $\begin{array}{c}\text { Norte- } \\
\text { américa }\end{array}$ & Europa & $\begin{array}{c}\text { Asia y } \\
\text { Oceanía }\end{array}$ & Sudamérica \\
\hline $\mathbf{1}$ & Ayuda para dejar de fumar & 0 & 1 & 0 & 0 \\
\hline $\mathbf{2}$ & Características negativas del tabaco & 2 & 1 & 0 & 0 \\
\hline $\mathbf{3}$ & $\begin{array}{l}\text { Complicaciones } \\
\text { embarazo/natalidad/feto/aborto }\end{array}$ & 2 & 1 & 2 & 1 \\
\hline $\mathbf{4}$ & Consecuencias negativas del tabaco & 8 & 11 & 2 & 2 \\
\hline $\mathbf{5}$ & Daño del tabaco a terceros & 4 & 3 & 2 & 1 \\
\hline $\mathbf{6}$ & Enfermedades cardíacas / cerebrales & 3 & 4 & 2 & 0 \\
\hline $\mathbf{7}$ & Enfermedades respiratorias & 2 & 2 & 1 & 1 \\
\hline $\mathbf{8}$ & Salud & 1 & 2 & 2 & 1 \\
\hline $\mathbf{9}$ & Salud Boca/dientes & 0 & 2 & 0 & 1 \\
\hline $\mathbf{1 0}$ & Salud cáncer & 2 & 1 & 3 & 2 \\
\hline $\mathbf{1 1}$ & Salud ventajas de dejar de fumar & 1 & 1 & 1 & 0 \\
\hline $\mathbf{1 2}$ & Sustancias tóxicas del humo & 2 & 0 & 0 & 0 \\
\hline $\mathbf{1 3}$ & Tabaco impotencia sexual y fertilidad & 1 & 1 & 0 & 1 \\
\hline
\end{tabular}




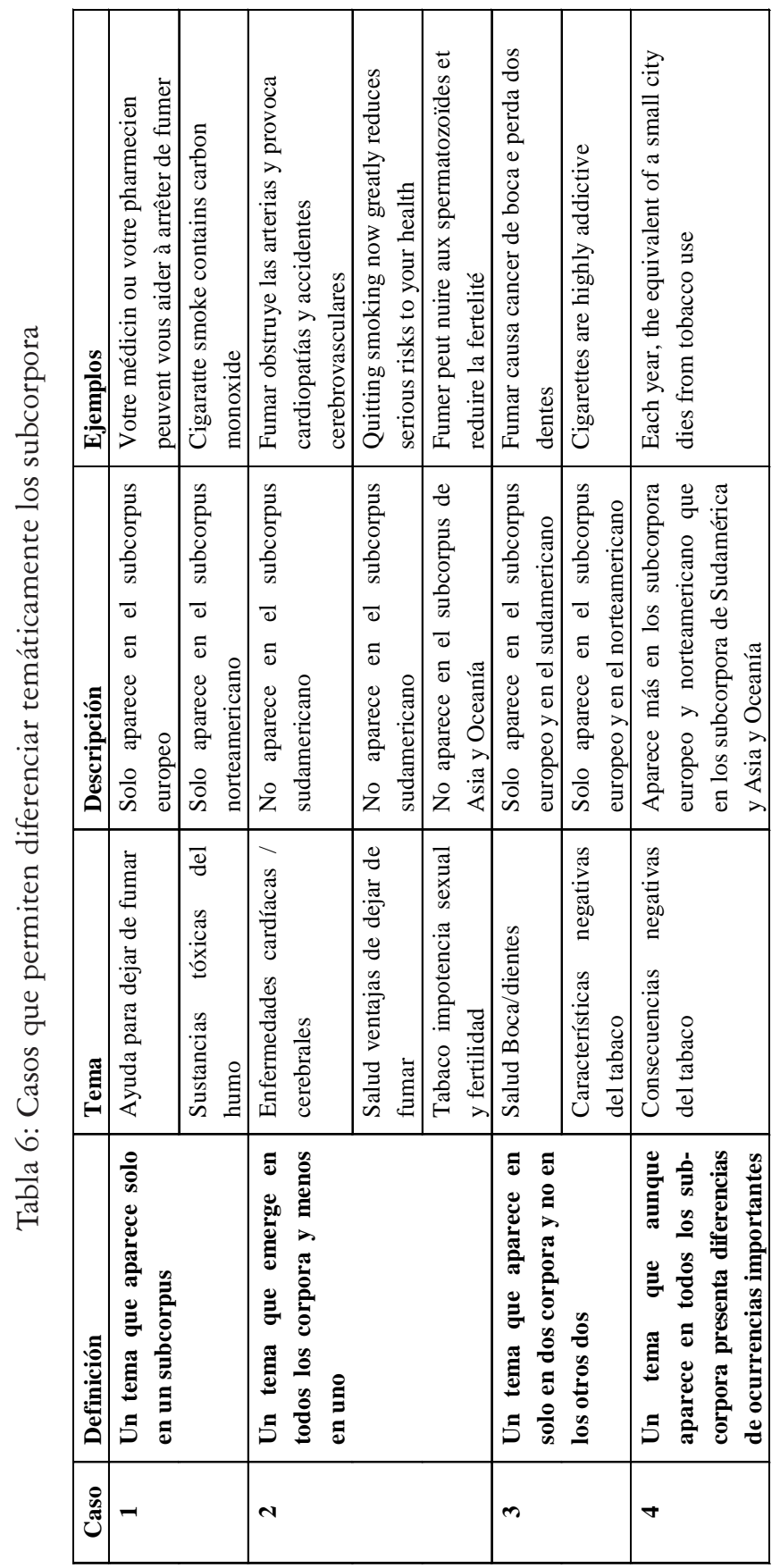


En primer lugar, analizaremos de modo general cuáles son los temas que más diferencian cada subcorpus. Así también, describiremos cuáles son los temas que más se repiten y que, por lo tanto, no constituyen categorías diferenciadoras al momento del análisis. Cabe señalar que, en algunos casos no se puede determinar que existan claras diferencias entre cada uno de los subcorpora pero sí entre subconjuntos de ellos. Estos casos serán señalados debidamente. A continuación, veremos cuáles son los continentes que presentan una mayor variabilidad de temas y, por último, examinaremos en detalle algunas cuestiones o aspectos problemáticos que no aparecen directamente representados (y que pueden resultar cuestionables en cuanto al método de clasificación) en la Tabla 5 pero que sí se pueden establecer al observar el análisis (que aparece en forma detallada por cada categoría en el Anexo 1). Con el objetivo de facilitar nuestra exposición, en la mayoría de los casos citaremos ejemplos de nuestro corpus de estudio.

\subsubsection{Temas que diferencian los subcorpora o subconjuntos de ellos}

$\mathrm{Al}$ analizar los temas emergentes que resultan ser diferenciadores de cada subcorpus o subconjuntos de ellos, aparecen, al menos, cuatro casos. Primero, un tema que aparece solo en un subcorpus. Segundo, un tema que emerge en todos los subcorpora y menos en uno. Tercero, un tema que aparece en solo en dos subcorpora y no en los otros dos y, cuarto, un tema que aunque aparece en todos los subcorpora presenta diferencias de ocurrencias importantes (aunque no necesariamente significativas) entre un subconjunto de subcorpora.

En la Tabla 6, se presenta una síntesis del análisis descrito.

\subsubsection{Temas recurrentes en todos los subcorpora}

En el análisis temático (Tabla 5) emergente del corpus de estudio, se puede observar que algunos temas aparecen de forma recurrente (esto es, aparecen en todos los subcorpora sin una diferencia de ocurrencias importante). Estos temas se constituyen como tópicos universales (lugares comunes) que, sin importar el continente, se utilizan para advertir en los mensajes de las cajetillas de cigarrillos en todo el mundo.

En la Tabla 7, se muestran estos temas con sus respectivos ejemplos. 
Tabla 7: Temas recurrentes en todos los continentes

\begin{tabular}{|l|l|}
\hline Tema recurrente & Ejemplos \\
\hline $\begin{array}{l}\text { Complicaciones } \\
\text { embrazo/natalidad/feto/aborto }\end{array}$ & $\begin{array}{l}\text { Smoking by pregnant women may result in fetal injury, } \\
\text { premature birth, and low birth weight } \\
\text { Smoking when pregnant harms your baby }\end{array}$ \\
\hline Daño del tabaco a terceros & $\begin{array}{l}\text { You're not the only one smoking this cigarette } \\
\text { Your smoking can harm others }\end{array}$ \\
\hline Enfermedades respiratorias & $\begin{array}{l}\text { Do your children cough? Children exposed to tobacco } \\
\text { smoke are more often affected by serious upper } \\
\text { respiratory infection }\end{array}$ \\
\hline Salud & $\begin{array}{l}\text { Tobacco seriously damages health } \\
\text { Fumar es perjudicial para la salud }\end{array}$ \\
\hline Salud cáncer & $\begin{array}{l}\text { Cigarettes cause lung cancer } \\
\text { El tabaco puede producir cáncer }\end{array}$ \\
\hline
\end{tabular}

Es interesante señalar que, no solo se trata de temas recurrentes, sino que también, muchos de estos temas constituyen mensajes que muchas veces tienen una traducción literal en uno y otro subcorpus.

\subsubsection{Variabilidad temática}

Para poder analizar de forma correcta la variabilidad temática de los mensajes de cada continente, se debe tener en cuenta tres puntos:

a) Los temas emergentes son 13 (ver Tabla 5).

b) La variabilidad temática depende de la cantidad de mensajes recolectados

c) Los aspectos que se señalan en el punto siguiente acerca de los detalles del método de clasificación temático

Tabla 8: Número de temas tratados en cada subcorpus

\begin{tabular}{|l|c|c|c|c|}
\hline & Norteamérica & Europa & Asia y Oceanía & Sudamérica \\
\hline $\begin{array}{l}\text { Total temas tratados } \\
\text { Por continente }\end{array}$ & 11 & 12 & 8 & 8 \\
\hline $\begin{array}{l}\text { Porcentaje respecto al } \\
\text { universo temático }\end{array}$ & $84,6 \%$ & $92,3 \%$ & $61,5 \%$ & $61,5 \%$ \\
\hline
\end{tabular}


La Tabla 8 contiene el total de temas tratados en cada subcorpus, los que deben interpretarse en referencia al total de temas emergentes del análisis (13). La variabilidad temática, entonces, se representa en este caso en un porcentaje respecto del total del espacio temático. Entre mayor sea ese porcentaje más variable es un subcorpus determinado. Hechos estos alcances, podemos observar, en primer lugar, que no existe ningún corpus que logre una variabilidad total, esto es, un subcorpus que trate el total de los temas emergentes. En segundo lugar, si consideramos este índice como un indicador de variabilidad temática, se deduce que el subcorpus europeo es el más variable, seguido por el corpus de Norteamérica. Tanto el corpus sudamericano como el de Asia y Oceanía presentan un mismo grado de variabilidad temática que en los dos casos se sitúa por debajo respecto a los otros subcorpora (el norteamericano y el europeo).

\subsubsection{Detalles respecto del método de clasificación temática}

Clasificar temáticamente nuestro corpus de estudio no ha sido, de ningún modo, una tarea fácil puesto que han surgido distintas complicaciones, que debilitan el concepto típico de clasificación, es decir, que cada unidad debe corresponder a una categoría de análisis. Dentro de las principales complicaciones que hemos enfrentado y que presentamos con el objetivo de superar las debilidades de nuestra clasificación y hacer más transparente nuestro estudio, se encuentran los siguientes aspectos:

a) Un mensaje puede referirse a más de un tema.

b) La separación de los temas es complicada, ya que muchos de los temas propuestos para nuestro análisis (ver Tabla 5) pueden subsumirse en otros.

c) Algunos de los temas son muy generales y no reflejan en última instancia la riqueza temática del corpus.

A continuación, se presentan algunos ejemplos de las complicaciones arriba mencionadas, junto con las decisiones (y sus justificaciones) tomadas en cada caso.

Algunos ejemplos del punto a) los constituyen los siguientes mensajes:

a.1) Smoking causes lung cancer, heart disease, emphysema, and may complicate pregnancy 
a.2) Stoppen met Roken vermindert het Risico op dodelijk Hart- en long ziekten ${ }^{3}$.

En un análisis a simple vista, podemos observar que los ejemplos de a. 1 y a.2 pueden corresponder simultáneamente a varios de los temas propuestos en la Tabla

En el primer caso podemos decir que se habla del cáncer, de enfermedades cardíacas y respiratorias y, además, de complicaciones durante el embarazo. Visto desde otra perspectiva, este mensaje también corresponde al tema propuesto denominado "consecuencias negativas del tabaco".

En el segundo caso a.2, ocurre algo similar. Se mezclan el tema de las enfermedades cardíacas y respiratorias (que en nuestra propuesta aparecen separadas). Asimismo, el mensaje puede ser clasificado dentro del tema que hemos llamado "ventajas de dejar de fumar".

La decisión tomada en estos casos fue clasificar los mensajes en los diferentes temas, pasando por alto la exigencia de una taxonomía excluyente, que aunque es más rigurosa, en este caso no representaba el fenómeno en su dimensión real. Desde este punto de vista, se debe ser cuidadoso al interpretar los resultados respecto del punto anterior, a saber, la variabilidad temática en cada subcorpus.

Respecto del punto b, que dice relación con la separación o estructuración temática jerárquica de los temas, podemos establecer que, en cierto sentido, la mayoría de los mensajes pueden subsumirse del tema general denominado "salud". Algunos ejemplos de que ilustran esta complicación, son los siguientes mensajes:

b.1) Fumar es malo para la salud

b.2) Dejar de fumar disminuye las crisis de salud

b.3) Smoking causes heart disease

Como ya mencionamos, todos los mensajes presentados en b, podrían, de una u otra forma, haberse subsumido dentro de un tema general denominado "salud". Sin embargo, creemos que una etiqueta general habría

3 Dejar de fumar disminuye el riesgo de enfermedades fatales cardíacas y respiratorias 
ocultado diferencias temáticas importantes. La decisión tomada entonces fue la de separar temáticamente estos mensajes tratando de manera que los temas atribuidos fueran más específicos. Así, el mensaje en b.1 quedó clasificado dentro del tema general que hemos denominado "salud" (ver Tabla 5). El mensaje b.2, fue clasificado con la etiqueta "ventajas de dejar de fumar", mientras que el mensaje b.3 quedó dentro del tema "enfermedades cardíacas y cerebrales".

Por último, en lo que se refiere al punto c, a saber, al carácter demasiado general de algunas etiquetas, resulta ser la arista contraria del punto b, esto es, categorías que no dan cuenta del todo de la especificidad temática de un mensaje. Las preguntas a las que nos debimos enfrentar fueron: ¿hasta qué punto debemos especificar temáticamente los mensajes? ¿Cuándo elegiremos una etiqueta más general? La respuesta que responde a estas dos preguntas, es decir, la decisión que tomamos fue que solo especificaríamos un tema en el caso de que estas subespecificaciones tuvieran una cantidad de ocurrencias importante. Para ilustrar mejor esta decisión, considérense los siguientes ejemplos:

c.1) Each year, the equivalent of a small city dies from tobacco use

c.2) Il fumo invecchia la pelle

c.3) Votre médicin ou votre pharmecien peuvent vous aider à arrêter de fumer

Aunque desde el punto de vista temático los mensajes c. 1 y c.2 se encuentran distantes, decidimos no postular categorías diferentes para su clasificación, ya que esto redundaría en la proliferación de etiquetas que no eran representativas numéricamente y nos dificultarían demasiado un análisis diferencial entre los subcorpora. Por lo tanto, ambos mensajes quedaron clasificados dentro de la etiqueta denominada "consecuencias negativas del tabaco". En cambio, en el caso del mensaje c.3, se decidió incluirlo en una etiqueta específica, ya que a pesar de estar clasificado dentro de una etiqueta temática que sólo tiene una ocurrencia, no podía subsumirse en ningún otro tema.

Como ya dijimos, debido a la complejidad de la clasificación hemos expuesto estos problemas, con el objetivo de visualizar el verdadero alcance de los resultados y hacer más transparente el análisis. Una forma de profundizar en esta problemática es la observación de la Red Conceptual Temática 1 (ver Anexo 1). 


\subsection{Procesos}

En la Tabla 9, se presentan los tipos de procesos que expresan los mensajes de nuestros corpus de estudio.

Tabla 9: Tipos de procesos por continente

\begin{tabular}{|c|c|c|c|c|c|}
\hline & Norteamérica & Europa & Asia y Oceanía & Sudamérica & Totales \\
\hline Causar & 11 & 14 & 7 & 6 & 28 \\
\hline Estar-ndo & 1 & 1 & 0 & 0 & 2 \\
\hline Llegar a un estado & 3 & 7 & 2 & 0 & 12 \\
\hline
\end{tabular}

Tal como se observa en la Tabla 9, el proceso de tipo "causar" es el que predomina (28) en nuestro corpus. Los procesos del tipo "estar-ndo" son los que tienen una menor presencia (2) en todo el corpus, mientras que los procesos del tipo "llegar a un estado" ocupan un lugar intermedio entre los dos anteriores (12). Todos los subcorpora, a excepción del subcorpus sudamericano, siguen esta tendencia general. El corpus europeo es el que tiene una mayor presencia de procesos causativos, mientras que el subcorpus menos causativo corresponde al sudamericano. Los procesos del tipo estarndo tienen un comportamiento similar en los subcorpora europeo y norteamericano con tan solo una ocurrencia respectivamente. Este tipo de proceso no aparece ni en el corpus asiático ni en el sudamericano. Por último, los procesos del tipo "llegar a un estado" son más frecuentes en el subcorpus europeo, seguido del corpus norteamericano y el asiático. Este tipo de procesos no aparece en el corpus sudamericano.

Los verbos desde los cuales se derivan estos procesos se presentan en la Tabla 10.

Tabla 10: Los verbos que actualizan los procesos

\begin{tabular}{|l|l|l|}
\hline \multicolumn{1}{|c|}{ Proceso } & \multicolumn{1}{|c|}{ Verbos } & \multicolumn{1}{c|}{ Ejemplos } \\
\hline Causar & $\begin{array}{l}\text { Causa, produce, provoca, } \\
\text { resulta, mata }\end{array}$ & Il fumo uccide \\
\hline Estar-ndo & Son & Cigarrettes are highly addictive \\
\hline Llegar a un estado & Reduce, aumenta, disminuye & $\begin{array}{l}\text { Smoking during pregnancy impedes the } \\
\text { growth of the fetus and increases the } \\
\text { risk of miscarriage }\end{array}$ \\
\hline
\end{tabular}


Tal como se deduce de las Tablas 9 y 10 la mayoría de los mensajes de advertencia en el mundo expresan procesos causativos que cumplen un esquema más o menos estable: $\mathrm{X}$ causa $\mathrm{Y}$. Donde $\mathrm{X}$ se refiere a la actividad de fumar, al humo del cigarro o al tabaco en general e $Y$ aparece actualizado como un estado una condición o consecuencia negativa. Un esquema similar se puede postular para los procesos del tipo "estar -ndo": X es Y. La regularidad que se cumple en este caso es la siguiente. $\mathrm{X}$ corresponde a entidades como el tabaco, los cigarrillos o a actividades (fumar, el uso del tabaco) e $\mathrm{Y}$ corresponde, recurrentemente, una característica negativa atribuida a X. El caso de los procesos del tipo llegar a un estado también pueden representarse con un esquema $\mathrm{X}$ e $\mathrm{Y}$, pero con una regularidad inversa. Cuando el proceso es positivo (aumentar, increase), $\mathrm{X}$ se refiere a la actividad de fumar e $\mathrm{Y}$ a un atributo negativo, tal como en el ejemplo de la Tabla 10. En cambio, cuando el proceso es negativo (disminuir, reducir), $\mathrm{X}$ se refiere al hecho de dejar de fumar e $\mathrm{Y}$, una atributo positivo respecto de $\mathrm{X}$.

Por último, es necesario señalar que, aunque no constituye un propósito de este estudio, puesto que sobrepasa los objetivos del mismo, existen diversas interacciones que se pueden establecer entre las distintas categorías de análisis. Comentamos esto, solo para ver algunas de esas interacciones en este caso de los procesos con la categoría de mitigadores del apartado de la modalización lingüística. No se puede determinar que un proceso causativo, por ejemplo, es igual entre uno y otro subcorpus, ya que en algunos casos estos procesos se presentan de forma mitigada. Para ejemplificar estos casos, considérense los siguientes mensajes:

a) Cigarettes cause lung cancer

b) El tabaco puede producir cáncer

Aunque en ambos casos se trata de procesos de tipo causativo, el mensaje $\mathrm{b}$ aparece mitigado, por lo que a pesar de implicar un proceso causativo este es más indirecto y débil que el mensaje a.

\subsection{Participantes}

En la Tabla 11, se muestra el tipo de participantes (animado o inanimado) que aparecen en los mensajes de advertencia en los distintos subcorpora. 
Tabla 11: Participantes animados e inanimados en el corpus

\begin{tabular}{|c|c|c|c|c|}
\hline & Norteamérica & Europa & Asia y Oceanía & Sudamérica \\
\hline Animados & 13 & 21 & 12 & 7 \\
\hline Inanimados & 11 & 3 & 1 & 1 \\
\hline
\end{tabular}

Tal como mencionamos anteriormente, el concepto de participantes se entiende en este estudio como los participantes semánticos que aparecen asociados a un evento que, a su vez, se actualiza por un verbo. El rasgo animado o inanimado se puede especificar para cada participante, según refieran a actividades o entidades que implican animalidad o bien señalen entidades que no son animadas.

Se debe especificar además, que un participante puede expresar animacidad implícitamente por hacer referencia indirecta a una entidad animada.

Más allá de las diferencias cuantitativas que existen, solo comentaremos cualitativamente un caso, que desde el punto de vista discursivo, nos parece más relevante. Para esto compárense los siguientes mensajes extraídos del subcorpus sudamericano:

a) El tabaco puede producir cáncer

b) Fumar es perjudicial para la salud

El mensaje a) presenta dos participantes, uno de carácter inanimado (el tabaco) y otro animado (cáncer). El mensaje b), en cambio, presenta dos participantes animados (de forma expresa o implicada), a saber, la actividad de fumar y la salud. Desde un punto de vista cognitivo (Talmy, 2000), se puede considerar que resulta más prominente que una actividad (como fumar) produzca un efecto que una entidad inanimada, de hecho, el mensaje a) debe reinterpretarse ya que el tabaco en sí no produce nada. La reinterpretación resulta más indirecta ya debemos inferir que no es el tabaco sino su consumo el que produce cáncer. Esta interpretación indirecta hace que consideremos que el mensaje a) tiene un carácter más débil e indirecto que el mensaje b).

\subsection{Categorías gráficas}

En la Tabla 12, se presentan los resultados del análisis del corpus según las categorías gráficas. 
Tabla 12: Porcentaje de ocurrencia de las categorías gráficas

\begin{tabular}{|c|c|c|c|c|}
\hline & Norteamérica & Europa & Asia y Oceanía & Sudamérica \\
\hline 1 mensaje & $25 \%$ & $0 \%$ & $100 \%$ & $28,6 \%$ \\
\hline 2 mensajes & $75 \%$ & $100 \%$ & $0 \%$ & $71,4 \%$ \\
\hline Frontal & $75 \%$ & $100 \%$ & $0 \%$ & $71,4 \%$ \\
\hline Lateral & $25 \%$ & $0 \%$ & $100 \%$ & $28,6 \%$ \\
\hline Tiene imagen & $75 \%$ & $0 \%$ & $0 \%$ & $71,4 \%$ \\
\hline No tiene imagen & $25 \%$ & $100 \%$ & $100 \%$ & $28,6 \%$ \\
\hline
\end{tabular}

Un punto que salta a la vista del análisis de las categorías gráficas de nuestro corpus es que existen regularidades importantes que nos permiten hacer generalizaciones amplias al respecto. Estas regularidades son intercategoriales y se pueden observar verticalmente, por lo que en este caso, más que fijarnos en la diferencias entre los subcorpora (que de igual forma se pueden deducir de la observación de la Tabla 12), nos centraremos en los patrones dentro de un mismo subcorpus.

Estas generalizaciones se enuncian a continuación:

a) Si el subcorpus presenta 1 mensaje por cajetilla, este se dispone en la parte lateral de ella y no presenta imágenes.

b) Si el corpus presenta dos mensajes por cajetilla, estos siempre aparecen en la parte frontal y en la mayoría de los casos (a excepción del corpus europeo), presenta una imagen. ${ }^{4}$

\subsection{Estadística básica}

En la Tabla 13, se presenta una estadística básica del corpus que pone en relación la cantidad total de mensajes $(\mathrm{N})$ con el número de palabras por mensaje (NP) para estimar el promedio de palabras por mensaje en cada subcorpus.

Tabla 13: Estadística básica del corpus

\begin{tabular}{|c|c|c|c|c|c|}
\hline & Norteamérica & Europa & Asia y Oceanía & Sudamérica & Totales \\
\hline $\mathbf{N}$ & 20 & 21 & 13 & 7 & 61 \\
\hline NP & 227 & 220 & 93 & 48 & 588 \\
\hline PPN & 11,35 & 10,48 & 7,15 & 6,86 & 8,9 \\
\hline
\end{tabular}

4 Es muy seguro, que en el corto plazo los mensajes europeos también presenten imágenes. 
Tal como se muestra en la Tabla 13, los mensajes norteamericanos y europeos son más y, a la vez, en promedio contienen una mayor cantidad de palabras que los mensajes de Sudamérica, Asia y Oceanía.

Aunque no se puede establecer una relación directa, entre estos resultados y la eficiencia que pueda tener una mayor cantidad de mensajes o su mayor o menor número de palabras, lo que sí resulta determinable es que en algunos grupos geográficos (Norteamérica y Europa) este tipo de textos tiene una presencia más marcada que en otros (i.e. Sudamérica y Asia y Oceanía).

\section{Conclusiones}

Las conclusiones de la investigación se basan en tres puntos. Primero, se presenta un pequeño resumen de los antecedentes históricos, expuestos al comienzo del trabajo. En un segundo punto, se muestran en una tabla las conclusiones para cada categoría utilizada en el análisis. El tercer y último punto tiene por objetivo sintetizar de forma más general estas conclusiones y relacionarlas con algunos aspectos de la historia contemporánea del uso del tabaco, tratados en el primer punto.

Tanto la historia precolombina como la historia de cómo el tabaco se introdujo en Europa (en 1556) demuestran que, en esos tiempos, el uso del tabaco estaba fuertemente asociado a una imagen positiva, como un producto con un gran poder medicinal y curativo. A comienzos del siglo XVII, específicamente en 1604 (ver King James I), surge un texto que se puede considerar como un antecedente directo de los mensajes que conforman el corpus de este estudio. La publicación de dicho texto supone el paso definitivo a una imagen negativa del consumo del tabaco en la historia contemporánea.

Tal como hemos visto en la primera parte de este estudio, los mensajes de advertencia se introducen durante la segunda mitad del siglo XX como una reacción a las distintas investigaciones que daban cuenta de una relación entre el uso del tabaco y su daño para la salud. En este contexto, los mensajes de advertencia aparecen por primera vez en 1966 en Estados Unido. Su uso comenzó casi paralelamente en Europa (1973). La tendencia mundial se desarrolló de modo que, al principio, solo había un mensaje y luego 
estos fueron variando y creciendo. En la actualidad, el uso de estos mensajes se ha masificado en gran parte del mundo oriental y occidental.

La historia contemporánea se abrió paso entre dos grandes columnas: su gran valor como producto comercial y su prohibición por instituciones sanitarias. En un comienzo, la mayoría de los estudios sobre los efectos del tabaco en la salud eran realizados por científicos de las propias compañías tabacaleras, que debían mantener en secreto bajo juramento sus investigaciones. Sólo hace muy poco tiempo (desde los años noventa), se han publicado o desclasificado los estudios realizados por esos científicos o por otros no pertenecientes a las compañías tabacaleras. Durante esos años también comenzaron a aparecer (en Estados Unidos y en el Reino Unido) diversas demandas civiles o estatales contra las compañías tabacaleras. Las acusaciones van desde alteraciones químicas, por parte de las tabacaleras, que vuelven más adictivo los productos; hasta demandas fiscales a esas compañías por manipular y fomentar el contrabando de tabaco como una forma de proteger el mercado.

Aunque son numerosas las investigaciones que se han realizado sobre estos desde los ámbitos legal y sanitario, los estudios desde una aproximación lingüística discursiva son casi nulos o inexistentes. Por medio de la comparación de un corpus multilingüe, en este estudio se abordó el fenómeno desde una perspectiva lingüística discursiva.

A partir del análisis de una serie de categorías descritas en los antecedentes teóricos, se compararon las subdivisiones por zonas geográficas. De los resultados obtenidos de ese análisis se puede concluir que, desde un punto de vista general, existen categorías que tienen un comportamiento constante y otras con un comportamiento más diferenciador en los 4 subcorpora que conforman el corpus general. Las primeras nos dan cuenta de las similitudes y las segundas de las diferencias.

En la Tabla 14, se presentan, a modo de síntesis, las conclusiones generales respecto a los resultados del análisis de las categorías. En la Tabla, se explicita además si el comportamiento de la categoría es homogéneo o variado en los distintos subcorpora. 
Tabla 14: Conclusiones generales por categoría

\begin{tabular}{|c|c|}
\hline $\begin{array}{l}\text { Categorías } \\
\text { de análisis }\end{array}$ & Conclusiones generales \\
\hline Tipos de Acto & $\begin{array}{l}\text { Los tipos de actos tienen un comportamiento homogéneo en todos los } \\
\text { subcorpora. Siempre priman los actos delocutivos, seguidos por los alocutivos. } \\
\text { Los actos elocutivos son escasos aparecen solo en un subcorpus. En el corpus } \\
\text { sudamericano la totalidad de los actos son del tipo delocutivo. La presencia de } \\
\text { estos actos implica un carácter más indirecto de la advertencia, ya que no se hace } \\
\text { referencia a ningún interlocutor específico. }\end{array}$ \\
\hline $\begin{array}{l}\text { Modalidades } \\
\text { enunciativas }\end{array}$ & $\begin{array}{l}\text { Respecto de las modalidades que especifican a los actos alocutivos se puede } \\
\text { concluir que, en la mayoría de los subcorpus, prima la interpelación sobre la } \\
\text { conminación y la prohibición. Esto implica que, cuando el mensaje se refiere a } \\
\text { otra persona, solo se le menciona (en relación a un contenido) pero no se le incita } \\
\text { o prohíbe realizar una acción. Esto también supondría una orientación más } \\
\text { debilitada de la advertencia en sí. } \\
\text { Respecto de las modalidades que especifican a los actos delocutivos se puede } \\
\text { concluir que priman la evidencia y la constatación sobre la posibilidad, la que } \\
\text { ocupa un número bajo de apariciones. En general, el comportamiento de estas } \\
\text { categorías es muy poco variable. }\end{array}$ \\
\hline $\begin{array}{l}\text { Modalización } \\
\text { lingüística }\end{array}$ & $\begin{array}{l}\text { En Europa y en Norteamérica, aparecen más enfatizadores que mitigadores en } \\
\text { contraposición a los mensajes de Sudamérica y de Asia y Oceanía. En estos dos } \\
\text { últimos subcorpora, los enfatizadores y mitigadores aparecen muy poco. Mientras } \\
\text { los enfatizadores se concretizan en distintas formas gramaticales (adjetivos, } \\
\text { adverbios, verbos), la totalidad de los mitigadores corresponden a verbos } \\
\text { modales. }\end{array}$ \\
\hline Temas & $\begin{array}{l}\text { Existen algunos temas que diferencian a un subcorpus o a un subconjunto de } \\
\text { ellos, en tanto aparecen o no en todos. Hay algunos temas que aunque aparecen } \\
\text { en cada uno de los subcorpus, presentan una diferencia en su frecuencia de } \\
\text { aparición. } \\
\text { Existen algunos temas que son recurrentes en todos los sucorpora. Estos temas } \\
\text { parecen ser lugares comunes universales que se utilizan en los mensajes en las } \\
\text { cajetillas de todo el mundo. } \\
\text { El proceso de clasificación temática es una tarea ardua que exige decisiones para } \\
\text { determinar hasta dónde se generaliza o se especifica en los nombres de las } \\
\text { etiquetas que se proponen. }\end{array}$ \\
\hline Procesos & $\begin{array}{l}\text { Los procesos más recurrentes en el corpus de estudio son del tipo causativo. } \\
\text { Nuevamente, estos procesos son más frecuentes en Norteamérica y Europa que } \\
\text { en Sudamérica y Asia y Oceanía. Existen algunas constantes esquemáticas en el } \\
\text { funcionamiento de los tipos de procesos que pueden representarse por medio de } \\
\text { una relación de un elemento X con uno Y. } \\
\text { Existen algunas diferencias en los tipos de proceso, en tanto interactúan con otras } \\
\text { categorías: no es lo mismo un proceso causativo (causa) que un proceso } \\
\text { causativo mitigado (puede causar). }\end{array}$ \\
\hline Participantes & $\begin{array}{l}\text { Los participantes animados son más frecuentes que los inanimados en todos los } \\
\text { sucorpora. La presencia de un elemento inanimado, en algunos casos, permite } \\
\text { suponer que la advertencia es más indirecta ("El tabaco pude producir cáncer" } \\
\text { versus "Fumar puede producir cáncer"). }\end{array}$ \\
\hline Gráficas & $\begin{array}{l}\text { Existe una interacción constante entre las categorías gráficas en todos los } \\
\text { sucopora: } \\
\text { Si el subcorpus presenta } 1 \text { mensaje por cajetilla, este se dispone en la parte lateral } \\
\text { de ella y no presenta imágenes. Si el corpus presenta dos mensajes por cajetilla, } \\
\text { estos siempre aparecen en la parte frontal y en la mayoría de los casos (a } \\
\text { excepción del corpus europeo), presenta una imagen. }\end{array}$ \\
\hline Estadística & $\begin{array}{l}\text { Los mensajes europeos y norteamericanos son más y más largos que los mensajes } \\
\text { de Sudamérica y Asia y Oceanía. }\end{array}$ \\
\hline
\end{tabular}


Tal como se observa en la Tabla 14, algunas de las categorías investigadas son claramente diferenciadoras de los grupos geográficos investigados. Otras, en cambio, presentan un comportamiento homogéneo en todas las zonas geográficas que incluimos en el corpus de análisis. Si recuperamos la idea propuesta al comienzo de la parte histórica, en la que postulamos que la historia contemporánea del uso del tabaco está determinada tanto por su valor comercial como por sus efectos negativos en la salud y relacionamos esa idea con las conclusiones expuestas en la Tabla 14; podemos postular que, algunos grupos geográficos se orientan más a una que a otra de las dos aristas que definen la historia contemporánea. Es decir, a partir del análisis de los mensajes, podemos deducir que existen grupos geográficos que restringen más que otros el uso del tabaco y, por lo tanto, le dan más libertad a su comercialización. Aunque existen excepciones (como el caso de Brasil, en el corpus sudamericano), la tendencia es que las zonas geográficas representativas de los países del primer mundo contienen mensajes más fuertes, directos, apelativos y menos modalizados que aquellos de los grupos geográficos compuestos por países del tercer mundo. Los mensajes son una expresión discursiva de las políticas antitabáquicas de las distintas zonas geográficas. Estas expresiones dejan ver que los países desarrollados consideran más que los países subdesarrollados los efectos negativos del tabaco. Aunque esto no supone necesariamente un efecto socioeconómico que derive en una baja de la comercialización de los productos del tabaco, sí puede estipularse que refleja un compromiso político más marcado en los países desarrollados, tendiente a restringir el consumo de dicho producto. En este sentido, tanto las condiciones de producción como de recepción de dichos textos permiten, por ejemplo, que en Europa se traten una mayor cantidad de temas o que en Sudamérica no aparezcan mensajes de tipo alocutivo que hagan referencia a un interlocutor determinado.

\section{Proyecciones y aplicaciones}

Dentro de las posibles proyecciones de este trabajo se encuentra la ampliación del corpus de estudio a otras zonas geográficas que no han sido incluidas. Esta ampliación se basaría no solo en la inclusión de otras zonas geográficas amplias (como África y Centro América), sino también de la adición de países específicos a las subdivisiones ya propuestas (como los 
países nórdicos en Europa, Rusia en Asia y Uruguay, Paraguay, Bolivia y Perú en Sudmérica).

Las aplicaciones que pueden derivarse de este trabajo se encuentran, principalmente, en el diseño de las políticas antitabáquicas de las autoridades sanitarias de los distintos países. Específicamente, las variables lingüísticas estudiadas pueden utilizarse para realizar investigaciones futuras respecto al impacto que estas puedan tener en el éxito de una campaña antitabaco. Así también para una autoridad sanitaria puede resultar interesante el análsisis comparativo de los mensajes de su país respecto de los mensajes de otras partes del mundo. Algunas de las preguntas que pueden investigarse teniendo en cuenta los resultados del presente estudio son:

¿Existe alguna relación entre el largo de los mensajes y su recuerdo o conciencia por parte de los consumidores?

¿Es la variabilidad temática una variable crítica respecto de los efectos que puedan tener los mensajes en la conducta de los fumadores?

¿La variabilidad temática que surge del análisis refleja realmente la realidad de las investigaciones que se llevan a cabo respecto al uso del tabaco?

¿Influye la cantidad de mensajes por cajetilla y su disposición (lateral o frontal) en la actitud de los fumadores respecto del uso del tabaco?

Las respuestas a estas preguntas deben ser proporcionadas por otras disciplinas aledañas a la lingüística y al análisis del discurso, entendiendo que superan los objetivos de la presente investigación.

Recebido em junho de 2005 Aprovado em novembro de 2005 E-mail: omar.sabaj@ucv.cl

\section{REFERENCES}

AnvisA, Brasil. 2000. Lei no 10167 [en línea]. Disponible en: http:// e-legis.bvs.br/leisref/public/showAct.php?id=470. 
BALLY, Charles. 1932. Linguistique générale et linguistique française. Paris: Ernst Leroux.

Borio, Gene. 2003. The tobacco timeline [en línea].Disponible en: http:/ /www.tobacco.org/resources/history/Tobacco_History.html.

CANADIAN COUNCIL FOR TOBACCO CONTROL. 2004. Canadian law and tobacco [en línea]. Disponible en http://www.cctc.ca

Charaudeau, Patrick. 1992. Grammaire du sens et de l'expression. Paris : Hachette Éducation.

Charaudeau, Patrick. \& Maingueneau, Dominique. 2002 (Dirs.). Dictionnaire d'analyse du discours. Paris: Seuil.

Ciapuscio, Guiomar. Ciapuscio, G. 1999. Tipos de textos. Buenos Aires: Ediciones de la Universidad de Buenos Aires.

Departamento de Justicia, Canadá. 1997. Tobacco Act [en línea]. Disponible en: http://laws.justice.gc.ca/en/T-11.5/106293.html.

Hammond, Davis; Fong, Geoffrey; MacDonald, Paul; Cameron, Roy \& BRown, Stephen. 2003. Impact of the graphic Canadian warning labels on adult smoking behaviour. Tobacco Control, 12: 391-395.

HEALTH CANADA. 2004a. Existing Health Warning Messages [en línea]. Disponible en http://www.hc-sc.gc.ca/hecs-sesc/tobacco/research/ smoking-4774/smoking_06.html.

. 2004b. New Health Warning Messages [en línea]. Disponible en http://www.hc-sc.gc.ca/hecs-sesc/tobacco/research/smoking-4774/ smoking_08.html.

. 2004c. Tobacco labelling [en línea]. Disponible en: http://www.hcsc.gc.ca/english/media/photos/tobacco_labelling/

HyLAND, Ken. 1998. Hedging in scientific research articles. Amsterdam: John Benjamins Publishing Company.

JaCKendoff, Ray. 1983. Semantics and cognition. London: The MIT Press.

Jakobson, Roman. 1985. Lingüística y poética. Madrid: Cátedra.

King James I. 1604. Counterblaste to tobacco [en línea]. Disponible en http://www.jesus-is-lord.com/kjcounte.htm.

KreEs, Günter \& van Leeuwen, Theo. 2001. Multimodal discourse: The modes and media of contemporary communication. London: Arnold.

PHILIP MORRIS INTERNATIONAL. 2004. Youth smoking prevention [en línea]. Disponible en http://www.philipmorrisinternational.com/ pages/eng/ysp/YSP.asp.

Sampieri, Roberto; Fernández, Carlos \& Baptista, Pilar. 2003. Metodología de la investigación. México: Mc Graw-Hill. 
TALMY, Leonard. 2000. Toward a cognitive semantics. London: Bradford. Titscher, Stefan; Meyer, Michael; Wodak, Ruth \& Vetter, Eva. 2000. Methods of text and discourse analysis. London: Sage.

Van Dijk, Teun. 1983. La ciencia del texto. Barcelona: Paidos.

Wegrzyn, John. 1999. An Appraisal of Health Warnings and Contents Labelling on Tobacco Products [en línea]. Disponible en http:// www.library.ucsf.edu/tobacco/batco/html/13200/13224/. 